\title{
An Analysis of Stative Verbs Used with the Progressive Aspect in Corpus-informed Textbooks
}

\author{
Serap Atasever Belli ${ }^{1}$ \\ ${ }^{1}$ Department of Foreign Language Education, English Language Teaching Program, Anadolu University, \\ Eskişehir, Turkey \\ Correspondence: Serap Atasever Belli, Faculty of Education, Department of Foreign Language Education, \\ English Language Teaching Program, Anadolu University, Eskişehir, 26470, Turkey. Tel: \\ 90-222-335-05-80-3498. E-mail: serapataseverr@hotmail.com
}

Received: October 27, 2017 Accepted: December 13, 2017 Online Published: December 15, 2017

doi: $10.5539 /$ elt.v11n1p120

URL: http://doi.org/10.5539/elt.v11n1p120

\begin{abstract}
This study was designed to investigate whether contemporary corpus-informed grammar textbooks written for English language learners and teachers presented the progressive use of stative verbs and if yes, which stative verbs were presented to occur with the progressive aspect and for which functions they took this aspect. A corpus of six electronic copies of corpus-informed textbooks was compiled and analyzed via AntConc. 3.2 .4 text analysis program to identify types and functions of stative verbs and calculate their occurrences. Overall, textbooks differed in their treatment of the progressive use of stative verbs and inclusion of the variety and numbers of types and functions. One remarkable finding was that the stative verbs taking the progressive aspect in all textbooks were found to be associated with emotions (i.e. love) whereas those not allowing progressive use were related to cognition (i.e. know). Another remarkable finding was that the textbooks which presented the highest numbers of stative verb types provided the most diverse functions whereas the textbooks which included the least numbers of stative verbs provided one or no function. Findings are hoped to raise awareness among textbook writers in making use of both the communicative messages motivated by the progressive use of stative verbs and the frequency and saliency information based on the corpus of present-day English to help learners grasp the changes in the language use.
\end{abstract}

Keywords: corpus-informed textbooks, stative verbs, progressive aspect, English native language, grammar

\section{Introduction}

Textbooks written for English language learners have been considered as a prominent source of input and practice and play a pivotal mediating role between the target language and the learner as they provide opportunity for learners to contact with the language (Richards, 2001; Razmjoo, 2007).

Considering the role of textbooks in language learning process, it is of utmost importance for textbook writers to provide learners with the language instances as used by native speakers of English and information about the grammatical features of the language. As language is dynamic and changing, textbook writers should introduce the changes in language and provide learners with the input frequently used in native English language (Hutchinson \& Torres, 1994). However, some researchers conclude that there are mismatches between present-day English language and the language presented in textbooks designed for English language learning (Römer, 2004; Khojasteh \& Reinders, 2013). According to Römer (2004), textbooks do not mirror native speaker language use and they present invented sentences of grammatical features. In addition, textbooks neglect salient features of present-day language frequently used by English native speakers (Khojasteh \& Reinders, 2013).

The discrepancies between the language of native speakers and the language in textbooks stem from the coverage of textbooks because it was determined based on textbook writers' intuition, anecdotal experiences and interests as well as prejudices of grammarians (Richards, 2001; Waugh \& Fonseca-Greber, 2002; Biber \& Conrad, 2010). In fact, textbook writers' intuitions or experiences are not always reliable and may be misleading in determining what to cover or which typical language choice to include in textbooks (Biber \& Conrad, 2010; Payne, 2011: xii). Moreover, grammar of a language is not prescriptive and does not consist of absolute categories or rules but it is rather a "dynamic and constantly changing set of habit patterns that allows people to communicate with one another" (Payne, 2011: xii). Thus, rather than relying on intuitions and adhering to the 
rules of prescriptive grammar, while designing contents of textbooks, writers are expected to cover the most frequently used forms and words with grammatical structure and instances that best illustrate the use and function in naturally occurring language (Biber \& Conrad, 2010). Here, the term 'naturally occurring language' refers to the present-day written and/or spoken language as it is used by native speakers of that language.

With the rise of corpus-based analyses of language as used by native speakers of English, the importance of language in use has been recognized and there has been a shift towards more pragmatic and data driven approach to language analysis (Biber \& Conrad, 2010; Payne, 2011). Through this shift, frequency information revealed through corpus analysis became important because the frequency of language features in the corpus of present-day language began to give an idea about which language feature is salient and what to cover and emphasize in teaching materials (Khojasteh \& Reinders, 2013). This recent shift has also led textbook writers to design textbooks based on the coverage of the most typical language features such as grammatical patterns and lexical words (Biber \& Conrad, 2010).

For instance, stative verbs such as understand, love, want, feel and etc., which were examined within the scope of this research, have been known for long as the verbs that cannot or rarely occur in the progressive form as a rule as evidenced in a number of previously written English textbooks (i.e. Quirk et al., 1972, 1985; Comrie, 1976; Biber et al., 1999; Downing \& Locke, 2006). Here, stative verbs are defined as the states that exist and remain as they are for an indefinite period of time and progressive aspect is "the combination of progressive meaning and nonstative meaning", used with actions rather than states to indicate temporariness, continuation and simultaneity (Quirk et al., 1972; Comrie, 1976: 35). In contrast to the incompatibility of stative verbs with the progressive according to previously written textbook wisdom (Anderwald, 2012), an insight into recent corpus-based studies has shown evidence for the frequent use of stative verbs with the progressive in native English language for a variety of functions and even a substantial increase in their use since the nineteenth century (i.e. Mair, 2006; Hermanova, 2010; Dráčková, 2011; Granath \& Wherrity, 2014). Accordingly, native speakers of English convey a variety of meanings by using stative verbs with progressive aspect such as signalling attitude, emotional involvement and immediacy of an utterance, annoyance (Granath \& Wherrity, 2014), showing politeness, temporariness, intensity of emotion, and the moment of speaking (Hermanova, 2010; Hodrmentová, 2011; Dráčková, 2011).

Having seen the evidence of corpus-based research on the increasing use of stative verbs with progressive aspect to serve a variety of functions in naturally occurring language contrary to the previously written textbook wisdom about the incompatibility of stative verbs with the progressive aspect, it is not known how recent corpus-informed textbook writers treat the issue of progressive use of stative verbs and which instances of progressive statives they show. In addition, it is also not known whether what textbooks writers making use of corpus depict related to the progressive use of stative verbs coincide with what the present-day English language depicts. Thus, to have an insight into this issue, there is a need to examine how the use of stative verbs with progressive aspect is treated in corpus-informed English grammar textbooks.

In this sense, it has been argued in the literature that textbooks lack comprehensive explanation about functions of progressive aspect and various uses of stative verbs with the progressive (Bland, 1988; Al-Shemmery, 2012; Granath \& Wherrity, 2014). Moreover, corpus-informed textbooks have not been studied in terms of how the issue of progressive use of stative verbs is dealt with. Thus, the coverage of progressive use of stative verbs in corpus-informed textbooks calls for a research. As grammar featured in contemporary textbooks should reflect the target language as it is currently used in native speaker language (Glisan \& Drescher, 1993), having an insight into the recent corpus-informed grammar textbooks designed for English language learners could provide with a better understanding of the progressive use of stative verbs.

The purpose of the current study is to reveal how stative verbs used with the progressive aspect were depicted in corpus-informed grammar textbooks designed for English language learners and teachers. Specifically, this study aimed to explore whether corpus-based textbooks present progressive use of stative verbs or not, and if yes, which stative verbs occurred in the progressive form and for which functions they took the progressive aspect.

\subsection{Literature Review}

As this study is mainly concerned with the analysis of stative verbs used with the progressive aspect, first, it is necessary to define the notion of aspect, specifically progressive aspect and then, to highlight what stative verbs denote and the cases that allow progressive use of stative verbs in native English language as claimed by grammarians, scholars and researchers. 


\subsubsection{Aspect and Progressive Aspect}

Aspect is defined as "the manner in which the verb action is regarded or experienced" (Quirk et al., 1972: 78). Aspect is a name given to the verb forms used to signify certain ways in which "an event is viewed or experienced" and English language possesses two aspects: perfect and progressive (Jacobs, 1995). Accordingly, perfect aspect denotes an event, which is completed whole whereas progressive aspect regards an event as 'being repeated intermittently' (Jacobs, 1995) as illustrated in the following examples respectively:

(1a) John read that book yesterday.

(1b) While he was reading it, the postman came.

(Comrie, 1976: 4)

Since the current study examined the use of stative verbs with the progressive, it is necessary to explain more specifically the notion of progressive aspect.

Progressive aspect, also called as durative, imperfective, or continuous aspect, refers to the constructions where ing- form of a verb follows a form of the verb to be (Comrie, 1976; Quirk et al., 1985; Leech et al., 2009). Progressive aspect is mainly used to serve three types of meanings (Quirk et al., 1985: 197-198). Accordingly, 'the happening has duration, the happening has limited duration and the happening is not necessarily complete' (p. 198). Moreover, meanings of the progressive are not limited to only these three meanings. Progressive aspect also expresses habituality and future action (Schubert, 2002; Jóhannsdóttir, 2011).

Progressive use has shown a remarkable increase in frequency in Modern and Late Modern English since the nineteenth century and changing use of progressive constructions along with increased range of meanings has received a lot of attention (i.e. Mair, 2006; Leech et al., 2009; Aarts et al., 2010; Kranich, 2010; Tumert, 2010; Freund, 2016). One of the factors affecting the increased frequency of the progressive is the tendency to use the progressive aspect frequently with stative verbs such as love, want, wish, realize and see (Mair, 2006; Leech et al., 2009; Aarts et al., 2010; Das, 2010; Dráčková, 2011).

As the main focus of this study was the progressive use of stative verbs, the following section clarifies what stative verbs denote and what circumstances allow the progressive use of stative verbs.

\subsubsection{Stative Verbs with the Progressive Aspect}

Stative verbs are defined as the verbs that generally describe a state or quality (Schubert, 2002: 25). They are stable and they lack shift or variation (Bland, 1988). In this sense, they refer to constant states and they are durative over time (Downing \& Locke, 2006: 354).

Stative verbs such as possess, know, understand, love, and want are claimed to resist the progressive because they denote static situations and lack internal structure as there are no stages progressing to an end (Bland, 1988; Schubert, 2002). Thus, stativity of stative verbs contradicts with the nonstativity of the progressive form (Comrie, 1976: 35). Stative verbs taking progressive aspect are argued to be even not grammatical (Kroeger, 2005). Despite this, certain stative verbs were claimed to occur rarely with the progressive aspect in certain exceptional cases in spoken language (i.e. Comrie, 1976; Quirk et al., 1985; Bland, 1988; Schubert, 2002). These exceptional cases and instances are illustrated below.

Firstly, stative verb might occur in progressive form if it takes a nonstative and dynamic meaning (Comrie, 1976; Palmer, 1988; Jacobs, 1995; Downing \& Locke, 2006). In this sense, Leech et al. (2009) argue that only the stative verbs, which allow both stative and dynamic interpretations, can occur in progressive constructions. The authors divided these verbs into four categories:

a) Perception and sensation (e.g. imagine, see, sound, hear, smell)

b) Cognition, emotion, attitude (e.g. think, feel, remember, hope, want, forget)

c) Having and being (e.g. be, have, cost, require, rely)

d) Stance (e.g. stand, live, lie)

(Leech et al., 2009: 129;130)

Here is an example of the stative verb 'to be' below in which it allows both static (2) and dynamic interpretation (3).

(2) Fred is silly.

(3) Fred is being silly.

(Comrie, 1976: 36)

In the instance (2), the perfect aspect is used to indicate that Fred is silly in general and this sentence does not imply that he is doing something silly at the moment of speaking. In contrast to static meaning of be in (2), the sentence (3) in which 'to be' is used in progressive aspect has dynamic interpretation and it implies that Fred is 
behaving as silly at the time of utterance. Here, the state is re-interpreted as an event to refer to the act of behaving in that way (Kroeger, 2005). Thus, there is a change in the meaning taking on dynamic characteristic when stative verb is used with progressive aspect (Comrie, 1976; Bland, 1988; Schubert, 2002).

Secondly, stative verbs can occasionally appear in the progressive form to express 'states changing by degrees' (Leech et al., 2009). In the instance of "I' $m$ understanding more about quantum mechanics as each day goes by" (Comrie, 1976: 36), the stative verb understand refers to a developing process and it is used nonstatively to indicate the change in the degree of understanding.

Another exceptional case is that some stative verbs might occur with the progressive 'to express intensity of emotion' (Comrie, 1976; Dráčková, 2011). In the instance of "I've only had six whiskies and already I'm seeing pink elephants.", the speaker is not seeing pink elephants but imagining things (Comrie, 1976: 37). Here, the progressive use of this stative verb indicates the intensity of feeling and emphasizes the emotive effect.

Fourthly, stative verbs can be exceptionally used in the progressive form to indicate temporary state (Quirk et al., 1985; Biber et al., 1999; Leech et al., 2009). In the example of "George is loving all the attention he is getting this week", the stative verb love is used to emphasize the feeling of loving lasting for a period of time in a limited duration (Kroeger, 2005: 153).

Next, stative verbs rarely occur in the progressive form to indicate politeness and to emphasize 'tentativeness' (Quirk et al., 1985; Schubert, 2002; Downing \& Locke, 2006). In the instance of "I was hoping you would give me some advice", the progressive use of hope expresses the attitude of speaker in a polite way (Quirk et al., 1985: 203).

Lastly, another reason for progressive use of stative verbs is to express habitual activity and emphasize repetition as illustrated below (Palmer, 1988:74; Dráčková, 2011):

(4) "Men have needs," that's what Francis used to say. "Needs". "So have I," I used to say.

But I don't think we were understanding each other. (Dráčková, 2011: 59)

In the extract (4) above, the stative verb understand is used with the progressive to signal the habitual activity lasting over a limited period of time and to stress repetition.

Briefly, according to grammarians and linguists (i.e. Comrie, 1976; Jacobs, 1995; Schubert, 2002; Downing \& Locke, 2006), although the aforementioned exceptional cases allow certain stative verbs such as see, love, and understand to rarely occur in progressive form especially in spoken language, most stative verbs such as seem, sound, know, want, belong, contain do not allow formation of the progressive in any case. As the current study aimed to analyze the progressive use of stative verbs in textbooks designed based on actual instances drawn from corpus of native English speakers, it is necessary to highlight what corpus-based evidence suggests related to the progressive use of stative verbs in the present-day English.

\subsubsection{Corpus-based Studies on the Progressive Use of Stative Verbs}

Prior to shedding a light on the corpus-based studies on the progressive use of stative verbs, it is necessary to explain the notion of corpus and what it refers to.

Corpus is defined as a collection of naturally occurring texts, written or/and spoken, compiled for a purpose and stored electronically (Hunston, 2002: 2) and 'a sample of living language' (Sinclair, 1991: 14). Corpus provides information about the frequency of language patterns in naturally occurring data as well as variation across a variety of sources such as spoken language and written language such as newspapers, magazines, fictions, and academic texts. It also helps to identify what is central and typical in the language (Sinclair, 1991). In this sense, Kennedy (1998) states that corpus information shows the most likely encountered language items by the language users and thus it is beneficial and it needs more attention and focus in language instruction.

Corpus-based studies have shown that many uses of the progressive form have increased their discourse frequencies since the nineteenth century especially with the increasing use of stative verbs in the progressive form in native American and British English (Smitterberg, 2005; Mair, 2006; Aarts et al., 2010; Kranich, 2010; Tumert, 2010). In relation to this evidence, Mair (2006: 89) states "there is currently a greater readiness than before to use the progressive form with stative verbs such as want or understand". Accordingly, there are many cases where stative verbs can easily take the progressive to convey a variety of meanings (i.e. Hermanova, 2010; Jóhannsdóttir, 2011). For instance, the study of Hodrmentová (2011) yielded frequent occurrence of stative verbs with the progressive in the present-day native English in British National Corpus (BNC) with a range of meanings such as expressing polite attitude, events limited for a period of time, and dynamic situations, backgrounding, showing superiority, and making whole discourse intensified in connection with degree 
modifiers. Furthermore, stylistic reasons, interpretive use, giving immediacy to generic statements, explanatory function and expressing increasing or decreasing activity of a verb were the other reasons for which stative verbs were used with the progressive (Dráčková, 2011). Here is an instance of 'believe' in the progressive form, which is used for stylistic and rhetorical reasons.

(5) ...for in believing this we are believing that when all the truths are in, our justification will remain...

(Dráčková, 2011: 64)

An insight into the native English language in corpus-based studies (i.e. Dráčková, 2011; Granath \& Wherrity, 2014; Vranovská, 2017) has also provided evidence for the progressive use of stative verbs which were previously argued not to occur with the progressive aspect in any case such as seem, sound, know, want, belong, and contain (i.e. Comrie, 1976; Jacobs, 1995; Downing \& Locke, 2006). For instance, want has been revealed to have an increasing frequency of use in progressive constructions in the present-day English language (i.e. Aarts et al., 2010; Hodrmentová, 2011) and even outnumbered other stative verbs such as realize, understand, like and love (i.e. Dráčková, 2011).

Furthermore, even though progressive use of stative verbs was assumed to be a feature of spoken language and less observed in writing, English written language also showed evidence for the frequent occurrence of stative verbs with the progressive (i.e. Dráčková, 2011; Granath \& Wherrity, 2014). Specifically, the progressive use of stative verbs was mainly observed in fiction as well as in spoken language, newspapers, magazine and academic texts (i.e. Hodrmentová, 2011; Dráčková, 2011; Granath \& Wherrity, 2014). For example, in the study of Dráčková (2011), stative verbs love and fear were found to occur with the progressive aspect predominantly in written mode.

In summary, recent corpus-based research has demonstrated that there is a dramatic increase in the frequency of progressive use of stative verbs and extension in their functions as well as an expansion in registers in the native English language. This case has demonstrated that there is a change in the English language and the scope of the progressive specifically with stative verbs has broadened (Aarts et al., 2010; Kranich, 2010; Jóhannsdóttir, 2011). Considering this change in the English language, Granath and Wherrity (2014: 21) claim that "the 'acceptability' of a given form does not depend on how closely it adheres to the rules of prescriptive grammar but to the communicative efficacy". In this sense, most of the stative verbs can freely occur in the progressive form "when a communicative need particular to a specific situation arises" in the native English language (Granath \& Wherrity, 2014: 21). Therefore, it is necessary for contemporary textbooks to reflect this change to help learners become pragmatically competent and communicate with native English speakers successfully (Waugh \& Fonseca-Greber, 2002; Römer, 2004). As the current study was designed to analyze recent textbooks written by writers making use of corpus, it is worth explaining the role of textbooks in language learning and teaching in the following section.

\subsubsection{The Role of Textbooks in Language Education}

Textbooks have been regarded as an important source of teaching and learning and they have represented the heart of English language teaching for years (Sheldon, 1988; Khodabakhshi, 2014). Regarding this, Hutchinson and Torres (1994:315) state the following:

"The textbook is an almost universal element of ELT teaching. Millions of copies are sold every year, and numerous aid projects have been set up to produce them in countries..."

Regarding the importance of textbooks in learners' language learning experience, Lam (2009: 262) states that "textbooks constitute the bread and butter of their language learning experience" because English language learners generally do not have opportunity to communicate with English native speakers in an English speaking environment. Thus, textbooks are the sources which are expected to supply learners with the right information in terms of the most common features of native speaker language to help them use it in pragmatically and socio-linguistically appropriate contexts (Lam, 2009).

However, an insight into studies on textbook analysis on various areas such as epistemic modality, discourse particle use, vocabulary, expression of agreement and modal auxiliary use has shown that the language reflected in textbooks do not match that of language that is in use (i.e. Holmes, 1988; Lam, 2009; López, 2009; Khojasteh $\&$ Reinders, 2013). These studies concluded that there were noticeable mismatches between textbooks and naturally occurring language in frequency and function of the language patterns analyzed. Accordingly, grammar explanations in textbooks are far from the reality of the native speaker language and textbooks include artificial contents, dialogues and conversations and thus fail to reflect the authentic language and lack reliability and accuracy (Glisan \& Drescher, 1993; Liu, 2008; Ming-yi, Fei-yu, \& Sy-ying, 2011). 
In fact, inauthentic language and invented sentences do not help learners learn the language and its conversational norms and communicate successfully (Vellenga, 2004). Inclusion of instances from naturally occurring English language in textbooks is of utmost importance because if grammar is to be taught for communicative purposes, textbooks are to present the structures that 'reflect the current-day native speaker discourse' (Glisan \& Drescher, 1993: 24). In this sense, Boxer and Pickering (1995) state the following:

"Only through materials that reflect how we really speak, rather than how we think we speak, will language learners receive an accurate account of the rules of speaking in a second or foreign language" (p. 56).

In parallel with this idea, grammar features in today's textbooks should reflect the target language as it is used currently by native speakers because only in this case, the type of grammatical information could be useful and beneficial for learners (Glisan \& Drescher, 1993).

In an attempt to provide present-day English language use, recently, there has been an increase in the production of contemporary corpus-informed language teaching and learning materials, specifically, textbooks putting the real language data at the core of language development (McCarthy \& O'Keeffe, 2010). The 'new' descriptive grammar in these textbooks is not radically different from the 'old' descriptive grammar in previously written textbooks; however, it is "fuller, richer and attested to by copious examples of "real English"” (Bourke, 2007: 47). These examples of naturally occurring language provided in the textbooks represent the most frequently and typically used language features, which are not accessible through the intuition of a textbook writer (McCarthy \& O'Keeffe, 2010). Thus, grammarians have recently begun to produce textbooks in which "grammar is informed by the corpus" of present-day English as corpuses "serve as a better basis from which to derive language teaching materials than the judgements made about a language by a single author' (Bourke, 2007: 46; Wong, 2010: 1255).

Considering the concern of the current study, although a review of textbooks designed in the past suggested that there were occasional uses of very few stative verbs with the progressive (i.e. Quirk et al., 1972; Comrie, 1976; Jacobs, 1995; Biber et al., 1999), it has not been revealed yet how contemporary corpus-informed textbooks designed for language learners depict stative verbs and their progressive use in the native English language. It is important to have an insight into the presentation of stative verbs used with the progressive aspect in corpus-informed textbooks since the recent corpus evidence has revealed a remarkable increase in the employment of stative verbs in progressive form for a range of reasons depending on the context they occurred in written and spoken current-day English. In addition, this study could contribute to our understanding of the range and scope of stative verbs used with the progressive aspect and provide implications for textbook designers and teachers about the issue of introducing progressive use of stative verbs to learners based on the analysis of corpus-informed textbooks.

To sum up, the purpose of the study is to provide a comprehensive account of the progressive use of stative verbs and the instances revealed in corpus-informed textbooks. The following research questions were addressed in this study:

1) Do the corpus-informed textbooks include the progressive use of stative verbs? If yes,

a. Which stative verbs are presented to allow the progressive use?

b. Which functions of progressive use of stative verbs are introduced in the corpus-informed textbooks?

2) Do the corpus-informed textbooks differ from one another in terms of types and functions of stative verbs used with the progressive aspect? If yes, how do they differ?

\section{Method}

This part presents an overview of the research design, data collection tools, and data collection and analysis procedure that was carried out for the purposes of this research.

\subsection{Research Design}

This study adopted a summative approach to qualitative content analysis. Through this research method, the content of the text data (e.g. textbooks) is subjectively interpreted via the systematic classification process which includes the identification and quantification of particular patterns or words under investigation to explore actual usage (Hsieh \& Shannon, 2005: 1278; 1283). Based on this method, the functions and frequency of stative verb types were determined based on the information provided in textbooks related to the progressive use. The sample of the study consisted of six corpus-informed grammar textbooks designed for English language learners and teachers, which was explained in the following section. 


\subsection{Corpus}

A corpus was compiled to collect data to meet the aims of the study. Here, the definition of Hunston (2002: 3) was adopted and the term corpus is used to refer to "a store of used language" collected for a purpose and stored electronically to study a certain aspect of language in use both qualitatively and quantitatively. For the purposes of the study, six electronic copies of corpus-informed grammar textbooks designed for English language learning and teaching were gathered and compiled in a corpus. Specifically, the parts analyzed within the scope of the study were the sections where the progressive aspect/construction/verbs, stative verbs, the present/past/ future progressive, past/present/perfect continuous tenses were explained.

The English corpus-informed textbooks were carefully selected based on the following criteria: the type of textbook, the inclusion of examples taken from native English corpus, the year of publication, major publishing companies with wider accessibility for use and difficulty level. Accordingly, they were chosen based on a review of textbooks that were designed by authors who made use of various native English corpuses, which reflected the target language as it is currently written and spoken. These textbooks include examples or items in exercises which were taken from the corpus of language in use that represent how English native speakers actually write and talk. The textbooks were selected among the contemporary textbooks written between 2005 and 2013. In addition, they were selected specifically from major publishing companies including Cambridge University Press, Pearson Longman, John Benjamins, Oxford University Press and Harper Collins UK since these publications were among the top-selling books and used as a source by millions of language learners and teachers in various parts of the world. Considering the world wide access to these textbooks by many people, it is important to highlight whether or how the textbooks differ in the treatment of the progressive use of stative verbs. As for the difficulty levels, these textbooks were mainly designed for advanced/high level learners and teachers or future teachers of English.

To begin with, one of the corpus-informed textbooks analyzed in this study was Real Grammar: A Corpus-based Approach to English. This textbook was written by Susan Conrad and Douglas Biber and published in 2009. It is based on "principled analysis of a large and carefully designed corpus" and provides English language learners with "the typical grammatical patterns frequently used by native speakers of English in speech and writing" (xi).

Secondly, the textbook "Understanding English Grammar: A Linguistic Introduction" written by Thomas E. Payne and published in 2011 was analyzed in the study. This grammar textbook is designed for English language learners as well as future teachers of English and 'provides hundreds of examples' obtained from two major corpora of English: The Corpus of Contemporary American English (COCA) and BNC Corpus (Payne, 2011: xiii).

The third corpus-informed grammar textbook was Advanced Grammar in Use which was written by Martin Hewings and published in 2013. The textbook was designed for advanced students of English based on the analysis of two corpora: Cambridge International Corpus which is a collection of multi-million words of real English in speech and writing and Cambridge Learner Corpus which is a collection of exam answers written by students (Hewings, 2013). Accordingly, grammar explanations and the examples in this book are prepared by using these two corpora.

The fourth corpus-informed grammar textbook was Collins COBUILD English Grammar which was written by Sinclair et al. and published in 2011. It is designed for English language learners and teachers based on the information in Collins Birmingham University International Language Database (COBUILD) corpus. This corpus was a 4 billion-word corpus including present-day English language in a number of registers such as books, websites, magazines, newspapers, and spoken data including everyday conversations, radio, and TV as well as new data added every month. The textbook provides grammatical explanations based on a wealth of examples that were drawn from the Collins corpus to illustrate the most typical grammatical patterns, contexts and vocabulary (pp. 3-7).

Another corpus-informed grammar textbook analyzed in the current study was Oxford Practical English Usage which was written by Michael Swan and published in 2005. It was designed both for teachers and higher-level students of English and had a full coverage of the grammar of English language. It was stated in the preface of the book that the explanations provided in this book also demonstrated 'the occasional exceptions to some grammatical rules' as these explanations deal with standard modern everyday British English (p. x). Accordingly, the examples of current English language usage provided in the textbook were checked against large electronic databases of corpora of written and spoken language (ix).

Lastly, the grammar textbook An Introduction to the Grammar of English (Revised Edition) was used in this research. It was written by Elly van Gelderen and published in 2010 for English language learners and it 
provides many contemporary example sentences that were drawn from COCA Corpus and BNC Corpus as well as Oxford English Dictionary and well-known plays (p. xv).

Table 1 below demonstrates the corpus-informed English grammar books which were analyzed within the scope of this study.

Table 1. Corpus-informed English grammar textbooks

\begin{tabular}{lll}
\hline Textbooks & Author/s & Publication Year \\
\hline Real Grammar: A corpus-based & Susan Conrad and Douglas Biber & 2009 \\
Approach to English & & 2011 \\
$\begin{array}{l}\text { Understanding English Grammar: A Linguistic } \\
\text { Introduction }\end{array}$ & Thomas E. Payne & 2013 \\
Advanced Grammar in Use & Martin Hewings & 2011 \\
Collins COBUILD English Grammar & Sinclair et al. & 2005 \\
Oxford Practical English Usage & Michael Swan & 2010 \\
An Introduction to the Grammar of English & Elly van Gelderen & \\
\hline
\end{tabular}

\subsection{Data Collection and Analysis Procedure}

Data collection and analysis procedure were carried out in three phases.

In the first phase, each corpus-informed textbook was compiled in separate word-document files. The format of each file was converted into plain text file (txt.) for analysis of the data in text analysis program.

In the second phase, the concordance program AntConc 3.2.4. tool was used to analyze textbooks in terms of stative verbs taking the progressive aspect. This tool is a program which allows researchers analyze manually language patterns as well as the contexts they occurred and calculate frequency of occurrences. Through this tool, first, the key words such as stative verb/s, progressive, progressive aspect/construction, continuous tense as well as the types of stative verbs such as see, hear, love, know, understand and so on. were searched in each textbook to detect instances of the progressive use. Each context where any of these keywords occurred was searched to reveal how stative verbs were treated regarding the progressive use. In addition, the types and functions were identified based on the cases that allowed progressive use of stative verbs, claimed by the grammarians and researchers of corpus-based studies aforementioned in the literature review part in this study (see Literature Review, Sections 1.1.2 and 1.1.3).

In the third phase, the occurrences of stative verbs found in each textbook were counted to determine the frequency of stative verbs that can be used/sometimes/almost never used with the progressive. Then, the findings obtained from the frequency and function analyses in six books were compared to find out whether these textbooks differed from one another or showed similarity in terms of types of verbs.

\section{Results}

Corpus-informed grammar textbooks were examined to reveal how stative verbs taking progressive aspect are depicted and the analysis of data revealed that there were both similarities and differences across six textbooks in the use of stative verbs taking progressive aspect. In this section, each stative verb found in each textbook was provided and the functions which stative verbs served in progressive use were explained and illustrated based on the instances obtained from the textbooks. Then, the similarities and differences across textbooks were highlighted and interpreted.

\subsection{Stative Verb Types Presented in Corpus-informed Grammar Textbooks}

In response to the research question 1, it was revealed that all textbooks presented the progressive use of stative verbs. Specifically, it was stated in textbooks that there were stative verbs which can be used in progressive form, can rarely/sometimes be used in progressive form and can almost never be used in progressive form. Table 2 below displays these stative verbs presented in each textbook. 
Table 2. Textbook analysis of progressive use of stative verbs

\begin{tabular}{|c|c|c|c|c|}
\hline \multirow[t]{2}{*}{ Textbooks } & \multicolumn{3}{|c|}{ Progressive Use of Stative Verbs } & \multirow[b]{2}{*}{ Total } \\
\hline & can be used & rarely/sometimes & almost never & \\
\hline $\begin{array}{l}\text { Advanced } \\
\text { Grammar in Use } \\
(2013)\end{array}$ & $\begin{array}{l}\text { understand, } \\
\text { (of/about), regret, realize, } \\
\text { find, consider (+ing), cost, } \\
\text { expect, feel, fit, have, } \\
\text { imagine, measure, appear, } \\
\text { weigh, want, hope, mean, } \\
\text { wonder about, look, like, } \\
\text { sound, intend, attract, love, } \\
\text { see }\end{array}$ & $\begin{array}{l}\text { know, agree, believe, } \\
\text { conclude, prefer, consist of, } \\
\text { doubt, own }\end{array}$ & $\begin{array}{l}\text { belong, dislike, } \\
\text { understand } \\
\text { (only in present } \\
\text { perfect } \\
\text { progressive form) }\end{array}$ & \\
\hline Total & 26 & 8 & 3 & 37 \\
\hline $\begin{array}{l}\text { Understanding } \\
\text { English Grammar: } \\
\text { A Linguistic } \\
\text { Introduction (2011) }\end{array}$ & see, love, be, like, know & - & - & \\
\hline Total & 5 & - & - & 4 \\
\hline $\begin{array}{ll}\text { Real Grammar: A } \\
\text { corpus-based } & \\
\text { Approach } & \text { to } \\
\text { English }(2009) & \end{array}$ & $\begin{array}{l}\text { think (with the past } \\
\text { progressive) }\end{array}$ & & $\begin{array}{l}\text { agree, believe, } \\
\begin{array}{l}\text { hear, see, want, } \\
\text { like, } \\
\text { conclude }\end{array}\end{array}$ & \\
\hline Total & 5 & - & 8 & 13 \\
\hline $\begin{array}{lr}\text { Collins } & \text { COBUILD } \\
\text { English } & \text { Grammar } \\
(2011) & \end{array}$ & $\begin{array}{l}\text { keep, want, hear, feel, smell, } \\
\text { be, have }\end{array}$ & $\begin{array}{l}\text { like, love, forget, guess, } \\
\text { imagine, lack, remember }\end{array}$ & & \\
\hline Total & 7 & 7 & - & 14 \\
\hline $\begin{array}{l}\text { An Introduction to } \\
\text { the Grammar of } \\
\text { English (2010) }\end{array}$ & - & - & know, be & \\
\hline Total & - & - & 2 & 2 \\
\hline $\begin{array}{lr}\text { Oxford } & \text { Practical } \\
\text { English } & \text { Usage } \\
(2005) & \end{array}$ & $\begin{array}{l}\text { think (of), wonder, look, } \\
\text { hope, see, have, smile, want, }\end{array}$ & $\begin{array}{l}\text { hear, feel, sound, wish, } \\
\text { understand, love, realize, } \\
\text { own, belong, consist, smell, } \\
\text { remember, taste, need, } \\
\text { mean, prefer, like }\end{array}$ & $\begin{array}{l}\text { believe, be, know, } \\
\text { dislike, contain, } \\
\text { agree, hate, }\end{array}$ & \\
\hline Total & 8 & 17 & 7 & 32 \\
\hline
\end{tabular}

As indicated in Table 2 above, a variety of stative verbs were presented in the textbooks. Accordingly, Advanced Grammar in Use and Oxford Practical English Usage textbooks provided the highest numbers of stative verbs with 37 and 32 types respectively. In contrast, the textbooks An Introduction to the Grammar of English and Understanding English Grammar: A Linguistic Introduction included the least numbers of stative verbs with 2 and 5 types respectively. In the former textbook, only know and be were presented and it was stated that progressive aspect is incompatible with these stative verbs (van Gelderen, 2010: 110) as illustrated below.

*He is knowing the answer.

*The book is being blue.

In the latter textbook (i.e. Understanding English Grammar: A Linguistic Introduction), these stative verbs, that 
are, be and know as well as see, like, love, were reported to be not completely ungrammatical when used with the progressive but that they 'constitute less-than-prototypical expressions' (p. 271).

As for the rest of the books, it was indicated that Real Grammar: A corpus-based Approach to English and Collins COBUILD English Grammar gave information about 13 and 14 stative verbs respectively as demonstrated in Table 2.

An insight into all textbooks showed that some stative verbs were found to be commonly mentioned: want, think, know, love, like, see, wonder, believe, hear, hope and feel as highlighted in Table 2 above. Even though these stative verbs were provided in all textbooks, their progressive use was treated differently across textbooks. For instance, in three textbooks, Oxford Practical English Usage, Collins COBUILD English Grammar and Advanced Grammar in Use, it was stated that want can be used with progressive aspect. In contrast, want was not allowed to take progressive aspect in any case in the textbook Real Grammar: A Corpus-based Approach to English

In addition, the analysis of another commonly mentioned stative verb know showed that know can never be used with the progressive in the textbooks such as Oxford Practical English Usage, An Introduction to the Grammar of English and Real Grammar: A corpus-based Approach to English. As for the textbook Understanding English Grammar: A Linguistic Introduction, the verb know may occur with the progressive aspect with dynamic interpretation.

Among the stative verbs mentioned in all textbooks, love and like were also examined and it was stated that they can take progressive aspect according to two textbooks called Advanced Grammar in Use and Understanding English Grammar: A Linguistic Introduction whereas they can be rarely used in progressive form according to two other textbooks called Oxford Practical English Usage and Collins COBUILD English Grammar.

Apart from the stative verb types, the functions for which stative verbs can be used with the progressive were also examined. The following section provides both the functions and the instances that illustrate each function obtained from each textbook.

\subsection{The Functions of Stative Verbs Taking the Progressive in Corpus-informed Textbooks}

The function analysis of stative verbs used with progressive aspect showed that a variety of functions were provided in the textbooks as demonstrated in Table 3.

Table 3. Functions of stative verbs taking the progressive in the corpus-informed textbooks

\begin{tabular}{ll}
\hline Textbooks & Functions \\
\hline Advanced Grammar in Use & to stress the temporariness of the situation
\end{tabular}

Advanced Grammar in Use

to stress the temporariness of the situation

to emphasize that we have recently started to think about something

to emphasize that we are not sure about something

\section{to describe actions /action meaning}

to stress that the situation lasts for a period of time at the moment of speaking

to talk about planned future event with firm intention or definite decision to do something

to talk about arranged activities or events in the future

(pp. 2-22)

\begin{tabular}{ll}
\hline $\begin{array}{l}\text { Understanding English Grammar: } \\
\text { A Linguistic Introduction (2011) }\end{array}$ & $\begin{array}{l}\text { to refer to the situations which are interpreted as active / (dynamic } \\
\text { meaning) (p. 292) }\end{array}$ \\
\hline $\begin{array}{l}\text { Real Grammar: A corpus-based } \\
\text { Approach to English (2009) }\end{array}$ & $\begin{array}{l}\text { to describe an action or a state that happens over an extended period of time } \\
\text { (p. 4) }\end{array}$ \\
\hline $\begin{array}{l}\text { Collins COBUILD English } \\
\text { Grammar (2011) }\end{array}$ & $\begin{array}{l}\text { to emphasize that a state is new or temporary } \\
\text { to focus on the present moment } \\
\text { to indicate someone's behavior at a particular time } \\
\text { to indicate that someone is doing something at a particular time } \\
\text { (p. } 458) .\end{array}$ \\
\hline
\end{tabular}


An Introduction to the Grammar of English (2010)

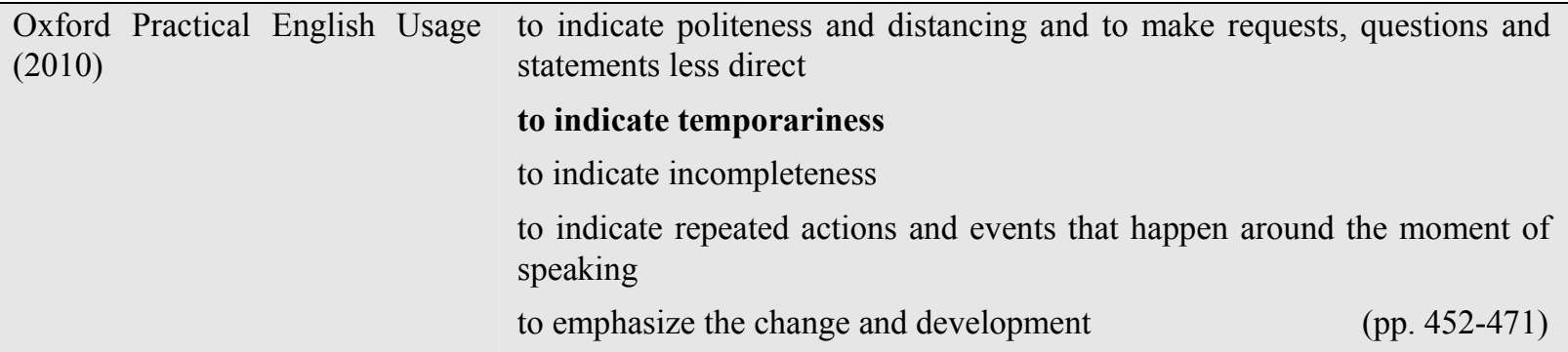

As indicated in Table 3, each textbook provided at least one function. Accordingly, Advanced Grammar in Use and Oxford Practical English Usage provided the most various types of functions that stative verbs taking progressive aspect served. Accordingly, the former included seven functions and the latter included five functions. Stressing the temporariness of the situation through progressive use of stative verbs was the commonly explained function in both textbooks as well as in Collins COBUILD English Grammar (2011) textbook as illustrated in the examples below:

1a. Ella's with us at the moment. The children are loving having her here.

(Advanced Grammar in Use, 2013, p. 2)

1b. I'm hoping you can lend me $€ 10$.

(Oxford Practical English Usage, 2012, p. 436)

1c. I'm liking grapes these days too.

(Collins COBUILD English Grammar, 2011, p. 218)

As seen in the extracts above, the stative verbs love, hope and like were used in progressive form to indicate temporary situation in the three textbooks aforementioned.

As for the rest of the functions, both Advanced Grammar in Use and Oxford Practical English Usage gave different functions of stative verbs in the progressive form. For instance, the functions of "indicating politeness and distancing", "making requests, questions and statements less direct", "indicating repeated actions and events that happen around the moment of speaking", and "emphasizing change and development" were only provided in Oxford Practical English Usage (2010) as illustrated below respectively:

2a. Good morning. I was wondering: have you got two single rooms? (p. 436)

2b. I was thinking- what about borrowing Jake's car? (p. 436)

2c. Jake's seeing a lot of Felicity these days. (p. 466)

2d. As I get older, I'm remembering less and less. (p. 471).

In the extract 2a, the stative verb 'wonder' was used with the progressive for politeness and in $2 \mathrm{~b}$, think was used in the progressive form to make the request less direct. In the other extract in $2 \mathrm{c}$, see was used to indicate that seeing Felicity happens around the moment of speaking as the time expression "these days" used in the extract demonstrates. In the last extract (2d), remember was used with the progressive to stress the change in the speaker's memory.

Additionally, the functions "emphasizing that we have recently started to think about", "talking about planned future event with firm intention or definite decision", "talking about arranged activities or events in the future" were only provided in Advanced Grammar in Use. The following extracts illustrating these functions were obtained from the textbook:

3a. I'm regretting my decision to give her the job. (p. 2)

3b. Are you seeing the doctor again next week? (p. 16).

$3 \mathrm{c}$. When the race starts later this afternoon the drivers will be hoping for drier weather than last year. (p. 22)

In the extract 3a, the verb regret took progressive aspect to emphasize that the speaker has started to feel regret about his/her decision in giving the job. Specifically, it was mentioned in the textbook that regret was used in the progressive form to indicate that the speaker is "increasingly aware that it was the wrong decision" (p. 2). In 
extract $3 b$, see was used with the progressive to emphasize that there is a planned future event with firm intention to do something. In the last extract $3 \mathrm{c}$, the verb hope was used with progressive aspect in future continuous form to talk about an arranged event in the future (p. 22).

As for the analysis of the rest of the textbooks, it was found out that only one function of progressive use of stative verbs was provided in two textbooks which are Real Grammar: A corpus-based Approach to English and Understanding English Grammar: A Linguistic Introduction. Accordingly, the function given in the former was "to describe an action or a state that happens over an extended period of time" ( $p .4)$ as illustrated below:

4a. I was thinking about bringing hiking boots, but they are so heavy.

(Real Grammar: A corpus-based Approach to English, 2009)

In $4 \mathrm{a}$, think was used with the progressive to indicate that the speaker is thinking of bringing boots over an extended period of time.

Considering the latter textbook (Understanding English Grammar: A Linguistic Introduction), the single function provided was "referring to the situations which are interpreted as active (dynamic meaning)". It was stated in the textbook that stative verbs can be used with the progressive on condition that a non-stative or dynamic sense is implied (p. 271). Specifically, the speaker can use stative verbs with the progressive when s/he has a communicative need to express a stative idea through dynamic interpretation (p. 292). This function was illustrated in the book through the instances of several stative verbs which were obtained from BNC Corpus. Table 4 displays the stative verbs and their meanings they took when they were used with the progressive.

Table 4. Instances of stative verbs with the progressive aspect in Understanding English Grammar: A Linguistic Introduction textbook (Payne, 2011: 292)

\begin{tabular}{ll}
\hline Progressive Use of Stative Verbs & Meaning \\
\hline We're seeing already, that Health Authorities haven't got the money... & Learning \\
The last time we were seeing each other it Oh! all ended in tears. & Dating \\
Yes they were seeing how much more they could eat and take home. & Determining \\
I was seeing them one after the other. & Interviewing \\
Football is a game of chance and I am loving every minute of it. & Enjoying participating \\
They're being rude up that end. & Acting rudely \\
they're being silly. & Acting silly \\
I'm being honest. & Speaking honestly \\
I thought I'd persuaded him that he was being foolish. & Acting foolishly \\
\hline
\end{tabular}

As illustrated above, the stative verbs see, love and be were used in progressive form and took on a dynamic meaning in each case as provided on the right side of Table 4. This function of progressive use of stative verbs was also explained in Advanced Grammar in Use textbook. According to the textbook writer, some stative verbs such as cost, expect, feel, fit, have, imagine, measure, appear, think, weigh have "both state and action meanings" and can occur in the progressive form if they have their action meanings as illustrated below (p. 2).

4b. Carley Robb is currently appearing in a musical on Broadway."

(Advanced Grammar in Use, 2013, p. 2)

The verb appear in extract $4 \mathrm{~b}$ had an active interpretation of the situation and it was used with progressive aspect to refer to its action meaning which is 'to take part'.

An analysis of "An Introduction to the Grammar of English" book showed that none of the functions provided in the rest of the textbooks were explained in this book.

To sum up, overall findings of the study showed that a variety of stative verbs which can be used, rarely/sometimes used and never be used with progressive aspect were provided in corpus-informed textbooks. In addition, a variety of functions for which stative verbs were used with progressive aspect were presented in the textbooks. Besides, the comparison among six textbooks yielded variation across textbooks in the inclusion of stative verb types and functions. 


\section{Discussion}

The present research has investigated the progressive use of stative verbs in six corpus-informed English grammar textbooks considering the types and functions and yielded both similarities and differences across textbooks in the numbers and diversity of stative verb types, their progressive use and functions.

Regarding similarities, based on the analysis of commonly mentioned stative verbs in all textbooks, it can be said that most of the verbs which can be used with the progressive aspect were the verbs which were associated with emotions (i.e. want, love, see, feel) whereas the rest of them which were 'not allowed to take progressive aspect' were the verbs associated with cognition (i.e. know). This finding suggests that stative verbs associated with emotion can take the progressive aspect whereas those associated with cognition almost never occur in the progressive form according to the textbooks analyzed in this study. In relation to this, in the study of Freund (2016), the author found statistically significant increase in the progressive use of the emotive verbs 'feel, love and hear' in the current-day colloquial British English language compared to the one twenty years ago and that the cognitive verb 'know' appeared to still resist to the progressive aspect. Similarly, the previous corpus-based research analyzing present-day English language in BNC Corpus and the Diachronic Corpus of Present-Day Spoken English revealed that verbs of emotion were frequently used in the progressive form while verbs of cognition were quite rare (i.e. Aarts et al., 2010; Hermanova, 2010; Dráčková, 2011; Hodrmentova, 2011). These parallelisms also show that verbs presented in the textbooks as the verbs that can be used in progressive form were the high-frequency stative verbs found in the progressive form in naturally occurring language whereas it is the opposite for the verbs which can never be used with the progressive. As this variation in progressive use of high and low-frequency stative verbs were introduced to language learners in all textbooks, this finding provides evidence for the importance of frequency information in the authentic language that is spoken or written by people today in natural situations.

As it is the case with the types of stative verbs, some functions such as emphasizing the temporariness of the situation and referring to the situations interpreted as active / dynamic were commonly explained in most of the textbooks for which stative verbs can be used with progressive aspect. With regard to this finding, in previous studies, some researchers concluded that these two functions were quite commonly employed functions in $B N C$ corpus and A Representative Corpus of Historical English Registers (i.e. Dráčková, 2011; Hermanova, 2010; Kranish, 2010). Moreover, the other functions which were provided in some of the textbooks such as to emphasize someone's behavior at a particular time, to emphasize that it happens over an extended period of time, and to talk about arranged activities or events in the future were also widely employed in present-day English language based on the findings of recent corpus-based studies on progressive use of stative verbs (i.e. Hermanova, 2010; Jóhannsdóttir, 2011; Granath \& Wherrity, 2014). This parallelism suggests that although the corpus-informed textbooks and corpus-based studies made use of different sources of present-day English language in different corpora, they share the same information about the functions which were frequent and salient in progressive use of stative verbs and they were introduced to language learners in corpus-informed textbooks.

Considering the differences, textbooks which presented the highest numbers of stative verb types provided the most diverse functions whereas the textbooks which included the least numbers of stative verbs provided one or no function. An insight into textbooks showed that the textbooks which provided rich numbers of stative verb types and functions were designed based on a variety of different corpora such as Cambridge International Corpus of multi-million words of real English in speech and writing, COBUILD corpus and corpus of standard modern everyday British English. However, an insight into the textbooks (i.e. An Introduction to the Grammar of English, Understanding English Grammar: A Linguistic Introduction) which presented the least numbers of stative verb types and provided one or no function showed that they were designed based on the same two corpora: COCA Corpus and BNC Corpus. In this regard, it is possible that these two corpora did not include the variety of types and functions and thus these two textbooks lacked the presentation of progressive use of stative verbs and functions. However, several researchers who investigated BNC corpus found a variety of functions which stative verbs served in progressive form (i.e. Hermanova, 2010; Hodrmentová, 2011; Dráčková, 2011). For instance, the study of Hodrmentová (2011) has shown that indicating politeness was one of the functions found in BNC corpus for which stative verbs can be used with the progressive, but this function was not provided in either of these two textbooks making use of BNC corpus. The unavailability of this function in textbooks may stem from that this function was not a widely used function or not salient in the data and thus not presented in textbooks. To have a better understanding of this finding, future research may investigate these two corpora based on which textbooks were designed and compare corpora results with textbooks to determine to what extent corpus findings related to functions of progressive use of stative verbs were reflected in these 
corpus-informed textbooks.

Bringing an insight into the recent corpus-informed English grammar textbooks is believed to shed a light into the progressive use of stative verbs in the English language as it is spoken/written today as these textbooks were designed based on the language as used by English native speakers. As Hutchinson and Torres (1994) stated, textbooks are valuable as "effective agents of change". Thus, it is essential for textbook writers to provide students with stative verb types and cover the functions to practice, which are salient in the language as used by English native speakers since this study highlighted that most of the textbooks covered a variety of stative verbs and functions frequent and salient in various sources of current-day English. However, salience or frequency information is not the sole factor that affects the progressive use of stative verbs. In relation to this, Granath and Wherrity (2014) argue that even if some stative verbs occur in the progressive form far less frequently, this is because of the reason that the communicative need specific to such situtations arises less frequently, the messages conveyed through them are less conventional and there are fewer such life conditions that call for these messages. Therefore, any stative verb can co-occur with the progressive when motivated by a message that required the progressive use to succeed in communicating that message. In this regard, context also plays a role in the choice of the progressive use of stative verbs. Thus, textbook writers can make use of both the communicative need in the context and the frequency information based on a variety of language sources to determine which function and types of stative verbs best illustrate the progressive use in present-day English to help learners grasp the changes and use the target language in pragmatically appropriate contexts. As Römer (2004) states, the more learners know about how a language works, the more confident they can be about its use.

As the scope of the present research is limited to the investigation of six grammar textbooks in the progressive use of stative verbs, future studies could analyze a larger sample of textbooks designed based on other sources of corpora to reveal whether corpus-informed textbooks cover similar stative verb types and functions or differ in the treatment of progressive use of stative verbs. Further research may compare corpus-informed textbooks with corpora of present-day English language based on which corpus-informed textbooks are designed to find out to what extent textbook writers present the most and/or the least frequently used stative verbs in the progressive form and the most commonly used functions.

\section{References}

Aarts, B., Close, J., \& Wallis, S. (2010). Recent changes in the use of the progressive construction in English. In B. Cappelle, \& N. Wada (Eds.) Distinctions in English grammar, offered to Renaat Declerck. Tokyo: Kaitakusha. (pp. 148-167).

Al-Shemmery, M. M. O. (2012). Investigating the Students' Awareness of Perception Verbs at the University Level. Journal of Babylon University, 20(4), 955-962.

Anderwald, L. (2012). "I'm loving it" - marketing ploy or language change in progress?. Presented at the Symposium: The pragmatics of aspect in varieties of English. https://doi.org/10.1080/00393274.2016.1208536

Biber, D., Johansson, S., Leech, G., Conrad, S., \& Finegan, E. (1999). Longman Grammar of Spoken and Written English. Longman: Pearson Education.

Biber, D., \& Conrad, S. (2010). Corpus Linguistics and Grammar Teaching. Pearson Longman English Language Teaching Newsletter.

Bland, S. K. (1988). The present progressive: Grammar vs. Usage Revisited. TESOL Quarterly, 22(1), 53-68. https://doi.org/10.2307/3587061

Bourke, J. M. (2007). Verbal complementation: A pedagogical challenge. Reflections on English Language Teaching, 6(1), 35-50.

Boxer, D., \& Pickering, L. (1995). Problems in the presentation of speech acts in ELT materials: The case of complaints. ELT Journal, 49, 44-58. https://doi.org/10.1093/elt/49.1.44

Corpus of Contemporary American English (COCA). Retrieved from www.americancorpus.org

Comrie, B. (1976). Aspect. Cambridge University Press: Cambridge.

Conrad, S., \& Biber, D. (2009). Real Grammar. A corpus-based Approach to English. Pearson: Longman.

Das, D. (2010). The Uses and Distribution of Non-progressive Verbs in Progressive Forms in English: A Corpusbased Study. In Proceedings of the 26th Northwest Linguistics Conference. Simon Fraser University, Canada. 
Downing, A., \& Locke, P. (2006). English Grammar. A university course. Routledge: New York.

Dráčková, J. (2011). Stative verbs with the progressive. (Unpublished MA thesis), Masaryk University, Czech Republic Retrieved from http://is.muni.cz/th/217145/ff_m/MA_Thesis.pdf

Freund, N. (2016). Recent Change in the Use of Stative Verbs in the Progressive Form in British English: I'm loving it. Language Studies Working Papers, 7, 50-61.

Glisan, E. W., \& Drescher, V. (1993). Textbook Grammar: Does It Reflect Native Speaker Speech? The Modern Language Journal, 7(1), 23-33. https://doi.org/10.1111/j.1540-4781.1993.tb01941.x

Granath, S., \& Wherrity, M. (2014). I'm loving you - and knowing it too: Aspect and so-called stative verbs. Rhesis: Linguistics and philology, 4(1), 2-22.

Hermanova, B. (2010). Stative verbs with the progressive. (Unpublished Bachelor's Diploma Thesis), Masaryk University, Czech Republic.

Hewings, M. (2013). Advanced Grammar in Use. Cambridge: Cambridge University Press.

Hodrmentová, L. (2011). Stative verbs with the progressive. (Unpublished MA Thesis), Masaryk University, Czech Republic.

Holmes, J. (1988). Doubt and certainty in ESL textbooks. Applied Linguistics, 9(1), 21-44. https://doi.org/10.1093/applin/9.1.21

Hsieh, H. F., \& Shannon, S. E. (2005). Three approaches to qualitative content analysis. Qualitative health research, 15(9), 1277-1288.

Hunston, S. (2002). Corpora in Applied Linguistics. Cambridge: Cambridge University Press. https://doi.org/10.1017/CBO9781139524773

Hutchinson, T., \& Torres, E. (1994). The textbook as agent of change. ELT Journal, 48(4). https://doi.org/10.1093/elt/48.4.315

Jacobs, R.A. (1995). English Syntax: A Grammar for English Language Professionals. New York, Oxford University Press.

Jóhannsdóttir, K. M. (2011). Aspects of the progressive in English and Icelandic. (Unpublished Phd Thesis), University of British Columbia, Canada.

Kennedy, G. (1998). An Introduction to Corpus Linguistics. Longman: London.

Khodabakhshi, M. (2014). Choose a Proper EFL Textbook: Evaluation of "Skyline" Series. Procedia - Social and Behavioral Sciences, 98, 959-967. https://doi.org/10.1016/j.sbspro.2014.03.505

Khojasteh, L., \& Reinders, H. (2013). How textbooks (and learners) get it wrong: A corpus study of modal auxiliary verbs. Applied Research on English Language, 2(1), 33-44.

Kranich, S. (2010). The Progressive in Modern English: A Corpus-Based Study of Grammaticalization and Related Changes. Amsterdam: Netherlands. https://doi.org/10.1163/9789042031449

Kroeger, P. R. (2005). Analyzing Grammar. An introduction. Cambridge University Press. UK. https://doi.org/10.1017/CBO9780511801679

Lam, P. W. Y. (2009). Discourse Particles in Corpus Data and Textbooks: The Case of Well. Applied Linguistics, 31(2), 260-281. https://doi.org/10.1093/applin/amp026

Leech, G., Hundt, M., Mair, C., \& Smith, N. (2009). Change in Contemporary English. A Grammatical Study. Cambridge University Press: New York. https://doi.org/10.1017/CBO9780511642210

Liu, D. (2008). Linking adverbials. An across-register corpus study and its implications. International Journal of Corpus Linguistics, 13(4), 491-518. https://doi.org/10.1075/ijcl.13.4.05liu

López, C. M. O. (2009). The lexical input in Bachillerato 2nd form students against the expected frequency list of a general English corpus. Universidad de la Rioja, Dialnet, 211-223.

Mair, C. (2006). Twentieth-Century English. History, variation and standardization. Cambridge University Press, Cambridge. https://doi.org/10.1017/CBO9780511486951

McCarthy, M., \& O'Keeffe, A. (2010). Historical Perspective: What are corpora and how have they evolved? In O'Keeffe, A., \& McCarthy, M. (eds). The Routledge Handbook of Corpus Linguistics. Routledge: New York. https://doi.org/10.4324/9780203856949.ch1 
Ming-yi, H., Fei-yu, W., \& Sy-ying, L. (2011). A Corpus-Based Analysis Comparing Vocabulary Input from Storybooks and Textbooks. The International Journal of Foreign Language Teaching, 25-33.

Palmer, F. R. (1988). The English Verb. Longman: London.

Payne, T. E. (2011). Understanding English Grammar. A Linguistic Introduction. Cambridge University Press: Cambridge.

Quirk, R., Greenbaum, S., Leech, G.\& Svartvik, J. (1972). A Grammar of Contemporary English. Longman Group.

Quirk, R., Greenbaum, S., Leech, G., \& Svartvik, J. (1985). A Comprehensive Grammar of the English Language. Longman: New York.

Razmjoo, (2007). High Schools or Private Institutes Textbooks? Which Fulfill Communicative Language Teaching Principles in the Iranian Context? The Asian EFL Journal Quarterly, 9(4), 126-140.

Richards, J. C. (2001). The role of textbooks in a language program. Guidelines, 23(2), 12-16.

Römer, U. (2004). Comparing real and ideal language learner input: The use of an EFL textbook corpus in corpus linguistics and language teaching. In G. Aston, S. Bernardini, \& D. Stewart (Eds). Corpora and Language Learners. John Benjamins Publishing Company: Amsterdam. https://doi.org/10.1075/scl.17.12rom

Schubert, S. H. (2002). Are you wanting a cup of coffee?: Overuse of the progressive aspect in Indian English. Konstazer Online-Publikations-System (KOPS).

Sheldon, L. E. (1988). Evaluating ELT textbooks and materials. ELT Journal, 42(4), 237-246. https://doi.org/10.1093/elt/42.4.237

Sinclair, J. (1991). Corpus, Concordance, Collocation. Oxford University Press: Oxford.

Sinclair, J., et. al. (2011). Collins COBUILD English Grammar. Digital Edition. Harper Collins UK.

Smitterberg, E. (2005). The progressive in 19th-Century English: A process of integration (Language and Computers: Studies in Practical Linguistics 54), 497-506. Rodopi: Amsterdam.

Swan, M. (2005). Practical English Usage. Third Edition. Oxford University Press: Oxford.

Tumert, L.R. (2010). Anti-progressive verbs in the progressive: Frequency changes across time and genres in American English. (Unpublished MA Thesis). The University of Oslo, Norway.

Van Gelderen, E. (2010). An Introduction to the Grammar of English. Revised Edition. John Benjamins Publishing Company: Amsterdam/Philadelphia. https://doi.org/10.1075/z.153

Vellenga, H. (2004). Learning Pragmatics from ESL \& EFL Textbooks: How Likely? TESL-EJ, 8(2).

Vranovská, D. (2017). Stative verbs with the progressive. (Unpublished MA Thesis). Masaryk University, Czech Republic.

Waugh, L. R., \& Fonseca-Greber, B. (2002). Authentic materials for everyday spoken French: Corpus linguistics vs. French textbooks. Arizona Working Papers in SLA and Teaching, 9, 114-127.

Wong, M. L-Y. (2010). Expressions of gratitude by Hong Kong speakers of English: Research from the International Corpus of English in Hong Kong (ICE-HK). Journal of Pragmatics, 42, 1243-1257. https://doi.org/10.1016/j.pragma.2009.09.022

\section{Copyrights}

Copyright for this article is retained by the author(s), with first publication rights granted to the journal.

This is an open-access article distributed under the terms and conditions of the Creative Commons Attribution license (http://creativecommons.org/licenses/by/4.0/). 